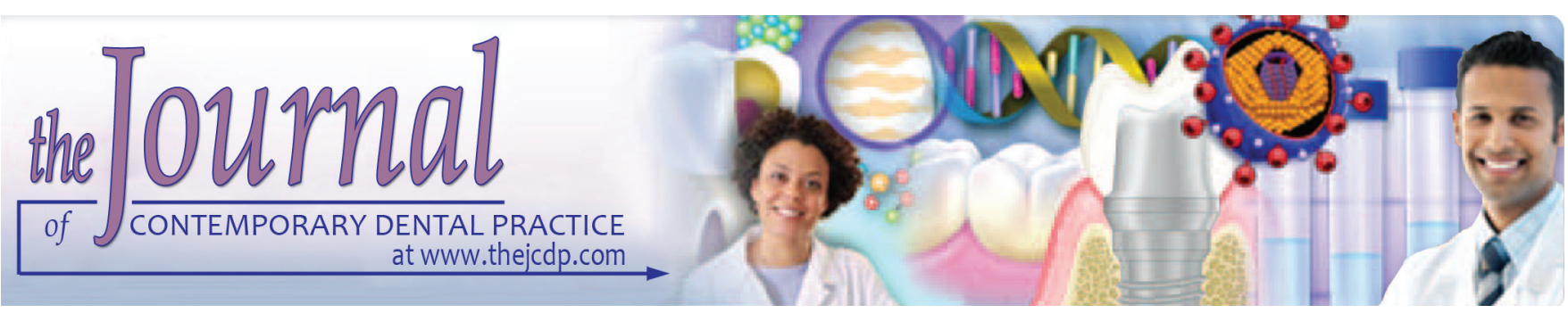

\title{
Prevalence of Dental Anomalies in Odisha Population: A Panoramic Radiographic Study
}

\author{
${ }^{1}$ Balasubramanya Goutham, ${ }^{2}$ Lipsa Bhuyan, ${ }^{3}$ Sangamesh N Chinnannavar, ${ }^{4}$ Madhurima Kundu \\ ${ }^{5}$ Kunal Jha, ${ }^{6}$ Shyam S Behura
}

\begin{abstract}
Aim: The aim of this study was to evaluate the prevalence of dental anomalies (DAs) in Odisha population using panoramic radiographs.

Materials and methods: In this study, 1,080 panoramic radiographs were evaluated for DAs. Dental records were reviewed for diagnostic confirmation. Anomalies related to the shape, size, position of teeth, and number of roots (supernumerary roots) were evaluated.
\end{abstract}

Results: The study results showed the prevalence of DAs to be $35.27 \%$. The most prevalent was dilaceration, which was seen in $46.71 \%$ cases followed by peg laterals in $20.99 \%$.

Conclusion: Dental anomalies were present in more than one-third of the study group, which was mostly related to shape of the teeth. Early diagnosis of these DAs helps in avoiding complications.

Clinical significance: Identification of DAs requires proper examination and thereby subsequent correct diagnosis. These anomalies can pose complications in normal functioning of orofacial complex. The knowledge of the prevalence of such anomalies aids dental practitioners for a proper treatment plan.

Keywords: Dental anomalies, Dilaceration, Microdontia, Panoramic radiographs, Transposition.

\footnotetext{
${ }^{1,5}$ Department of Public Health Dentistry, Kalinga Institute of Dental Sciences, Kalinga Institute of Industrial Technology University, Bhubaneswar, Odisha, India

${ }^{2,6}$ Department of Oral Pathology and Microbiology, Kalinga Institute of Dental Sciences, Kalinga Institute of Industrial Technology, University, Bhubaneswar, Odisha, India

${ }^{3}$ Department of Oral Medicine and Radiology, Kalinga Institute of Dental Sciences, Kalinga Institute of Industrial Technology University, Bhubaneswar, Odisha, India

${ }^{4}$ Department of Oral Pathology and Microbiology, Kalinga Institute of Dental Sciences, Kalinga Institute of Industrial Technology University, Bhubaneswar, Odisha, India

Corresponding Author: Shyam S Behura, Department of Oral Pathology and Microbiology, Kalinga Institute of Dental Sciences, Kalinga Institute of Industrial Technology University Bhubaneswar, Odisha, India, Phone: +919178358687, e-mail: dr.shyamsb@gmail.com
}

How to cite this article: Goutham $B$, Bhuyan $L$, Chinnannavar SN, Kundu M, Jha K, Behura SS. Prevalence of Dental Anomalies in Odisha Population: A Panoramic Radiographic Study. J Contemp Dent Pract 2017;18(7):549-553.

Source of support: Nil

Conflict of interest: None

\section{INTRODUCTION}

The development of tooth is a complex process, in which more than 300 genes have been known to be expressed. ${ }^{1}$ Disturbances occurring during this process can result in dental anomalies (DAs) of tooth which can change the shape, size, structure, number, and their eruption patterns. ${ }^{2}$ These alterations may be primary or arise secondary to environmental influences, certain genetic alterations, prenatal, and postnatal events like mineralization or maturation of the three mineralized components of the tooth, i.e., enamel, dentin, and the cementum. ${ }^{3-5}$

Dental anomalies usually cause malocclusion and affect the organization of the dental arches which in turn cause difficulties in dental treatment ranging from a simple extraction to root canal procedure. ${ }^{6}$ Therefore, knowledge on identification and prevalence of DAs helps the dental practitioners improve the treatment plan. Permanent dentition anomalies, when compared to the deciduous counterpart, are known to cause both shortand long-term complications which can lead to irreversible damages. ${ }^{7}$ These anomalies may involve or arise in a single tooth or may be a part of systemic disorder or a syndrome that arise generalized to involve all the teeth. ${ }^{8}$

Review of the literature has shown varying data on the prevalence of these DAs. The discrepancies in the data may be attributed to racial differences, different sampling techniques, and different diagnostic criteria., ${ }^{2,-11}$ Knowledge on prevalence and incidence of DAs can also provide information for genetic and phylogenic studies, 
which can further help the researchers in understanding the difference in different study populations. The aim of this study was to determine the prevalence of DAs in permanent dentition of Odisha population using orthopantomographs (OPG).

\section{MATERIALS AND METHODS}

The retrospective study consisted of 1,080 OPGs of individuals (540 males and 540 females) with known age and gender taken during the period of February 2014 to February 2016. The age ranged between 18 and 62 years. The OPGs for the study were obtained from the archives of the Department of Oral Medicine and Radiology, Kalinga Institute of Dental Sciences. Ethical Committee approval was obtained. The OPGs were taken with Myray Hyperion XQ Digital Machine (Italy), by the magnification factor of $1: 1$.

The OPGs showing any pathology, trauma, fracture which affected the normal growth of permanent dentition, poor quality panoramic radiographs, syndromic patients and OPGs of patients not native of Odisha were excluded from the study population. Good quality OPGs were included in the study.

Computerized screening ( $\mathrm{HP}$, Windows 7 professional, SP1 2.6GH2) of the OPGs was done to determine the DAs. The screening was done by a single radiologist with a limit of 20 radiographs a day. The DAs detected were root dilaceration, peg-shaped lateral incisors, talon cusp, concrescence, microdontia, supernumerary roots, transposition, and congenitally missing teeth.

\section{RESULTS}

The study comprised 540 males and 540 females with an age range of 18 to 62 years. Of the 1,080 cases evaluated, 381 cases $(35.27 \%)$ had at least one DA. Dilaceration of the roots was the most prevalent DA (16.48\%) encountered followed by peg-shaped lateral incisors (7.41\%) and congenitally missing teeth $(4.07 \%)$. Table 1 shows

Table 1: Distribution of patients and prevalence of different dental anomalies according to gender

\begin{tabular}{llll}
\hline $\begin{array}{l}\text { Types of dental } \\
\text { anomaly }\end{array}$ & $\begin{array}{l}\text { Males } \\
(n=540)\end{array}$ & $\begin{array}{l}\text { Females } \\
(n=540)\end{array}$ & $\begin{array}{l}\text { Total } n=1080 \\
(\% \text { prevalence })\end{array}$ \\
\hline $\begin{array}{l}\text { Root dilaceration } \\
\text { Taurodontism }\end{array}$ & 85 & 93 & $178(16.48)$ \\
$\begin{array}{l}\text { Peg-shaped lateral } \\
\text { incisors }\end{array}$ & 41 & 1 & $39(0.28)$ \\
Talon cusp & 3 & 1 & $80(7.41)$ \\
Concrescence & 1 & 0 & $4(0.37)$ \\
Microdontia & 16 & 9 & $1(0.09)$ \\
Transposition & 22 & 15 & $25(2.31)$ \\
Congenitally missing & 24 & 20 & $37(3.43)$ \\
teeth & & & $44(4.07)$ \\
\hline Total & 198 & 183 & $381(35.27)$ \\
\hline
\end{tabular}

Table 2: Frequency of dental anomalies in the study population

\begin{tabular}{llll}
\hline Variables & Males & Females & Total $n=1080(\%)$ \\
\hline Patients with one anomaly & 161 & 162 & $323(29.90)$ \\
Two anomalies & 26 & 13 & $39(3.61)$ \\
$>$ Two anomalies & 11 & 8 & $19(1.76)$ \\
\hline Total & 198 & 183 & $381(35.27)$ \\
\hline
\end{tabular}

the prevalence of different DAs according to gender. Root dilacerations and supernumerary roots were more prevalent in females, while the other anomalies were predominantly severe in males.

Table 2 shows the frequency of DAs among the study population, $323(29.9 \%$ ) patients had one DA followed by $39(3.61 \%)$ patients with two anomalies and $19(1.76 \%)$ with greater than two anomalies.

\section{DISCUSSION}

Dental anomalies of tooth can vary from a mild developmental delay to the most severe tooth agenesis. ${ }^{11}$ The etiology of these has been suggested to be genetic and hereditary, as derived from studies in families, monozygotic twins, and from the frequent observation of associations of certain DAs. ${ }^{12}$ Dental anomalies should be diagnosed at the earliest as they might complicate the treatment plan as in the case of any orthodontic or endodontic procedures.

Baccetti ${ }^{13}$ found that $34 \%$ of the patients with conicalshaped upper lateral incisors had palatally displaced canine, and dilacerations of root can cause difficulty in root canal therapy and extractions. Root canal filling becomes challenging in taurodontism because of the complexity of the root canal anatomy and the proximity of the buccal orifices. ${ }^{14}$

Many studies were conducted in the past to find out the prevalence of each of these DAs worldwide, and each study showed few variations in the data which may be due to ethnic and sampling differences. Our study was conducted to determine the prevalence of DAs using the panoramic radiographs of patients with known age and sex in Odisha population. Table 3 shows the comparison of DAs encountered in the present and previous studies.

The prevalence of DAs in our study was about $35.27 \%$, which was almost near to the study conducted by Patil et $\mathrm{al}^{15}$ in Jodhpur which was $36.7 \%$. Similar studies done by Afify and Zawawi ${ }^{8}$ and Goncalves-Filho et $\mathrm{al}^{9}$ showed a prevalence of 45.1 and $56.9 \%$, which was higher in comparison to our study.

The most prevalent DA in our study was root dilaceration which was present in $46.71 \%$ of cases. The prevalence of root dilaceration was $14.01 \%$ in a study conducted by Goncalves-Filho et $\mathrm{al}^{9}$ and $22.5 \%$ by Guttal et al. ${ }^{7}$ Root dilaceration refers to angulation or a sharp bend or curve in the root which is thought to occur due to trauma 
Table 3: Comparison of dental anomalies encountered in the present and previous studies

\begin{tabular}{|c|c|c|}
\hline Dental anomaly & $\begin{array}{l}\text { Present study } \\
\text { (Prevalence \%) }\end{array}$ & $\begin{array}{l}\text { Previous studies } \\
\text { (Prevalence \%) }\end{array}$ \\
\hline Root dilaceration & 16.48 & $\begin{array}{l}14.01 \text { - Goncalves- } \\
\text { Filho et al } \\
22.5 \text { - Guttal et al }\end{array}$ \\
\hline $\begin{array}{l}\text { Peg-shaped lateral } \\
\text { incisors }\end{array}$ & 7.41 & 0.8-8.4-Chanchala \\
\hline $\begin{array}{l}\text { Congenitally missing } \\
\text { teeth }\end{array}$ & 4.07 & 11.3 - Dhanrajani \\
\hline Transposition & 3.43 & $\begin{array}{l}0.09-1.4- \\
\text { Papadopoulos et al }\end{array}$ \\
\hline Microdontia & 2.31 & $0.8-9.14-$ Guttal et al \\
\hline Talon's cusp & 0.37 & 1-8 - Shrestha et al \\
\hline Taurodontism & 0.28 & $\begin{array}{l}27.19 \text { - Goncalves- } \\
\text { Filho et al } \\
8 \text { - Darwazeh et al }\end{array}$ \\
\hline Concrescence & 0.09 & $\begin{array}{l}0.63 \text { - Goncalves- } \\
\text { Filho et al }\end{array}$ \\
\hline
\end{tabular}

(Figs 1A to C). Root dilaceration is thought to be a limitation in orthodontic treatment, ${ }^{5}$ and they present difficulties at the time of extraction. ${ }^{16}$

Peg-shaped laterals refer to a conical-shaped lateral incisor with a sharp and acute edge, which is broadest cervically and tapers incisally to a blunt point, and the prevalence varies from 0.8 to $8.4 \%$ whereas in our study the prevalence was $7.41 \%$, which was the second common anomaly. ${ }^{2,17}$

Failure of teeth to form is noted to be one of the most common DA encountered with a prevalence of 1.6 to $11.3 \%$. Our study showed a prevalence of $4.07 \%$ congenitally missing teeth, which is in consistent with the previous studies. ${ }^{3,18}$

Tooth transposition is a rare DA where there is a positional interchange of two neighboring teeth, or the development or eruption of a tooth in a position normally occupied by a nonneighboring tooth. Hence, tooth transposition can be considered as a peculiar type of ectopic eruption in which each ectopic tooth changes the normal order of the tooth sequence in the dental arch, and the prevalence is 0.09 to $1.4 \% .{ }^{19}$ Our study showed a high prevalence of $9.71 \%$.

The term microdontia should be applied only when the teeth are smaller than usual (Figs 1A to C). In our study, the prevalence of microdontia is $2.31 \%$ and it was in the range of 0.8 to $9.14 \%$ according to Neville et $\mathrm{al}^{3}$ and Guttal et al. ${ }^{7}$ Macrodontia means relatively larger tooth than the normal. Its occurrence is very low; $>1 \%$ of population. ${ }^{9}$ In our study, there were no cases with this anomaly.
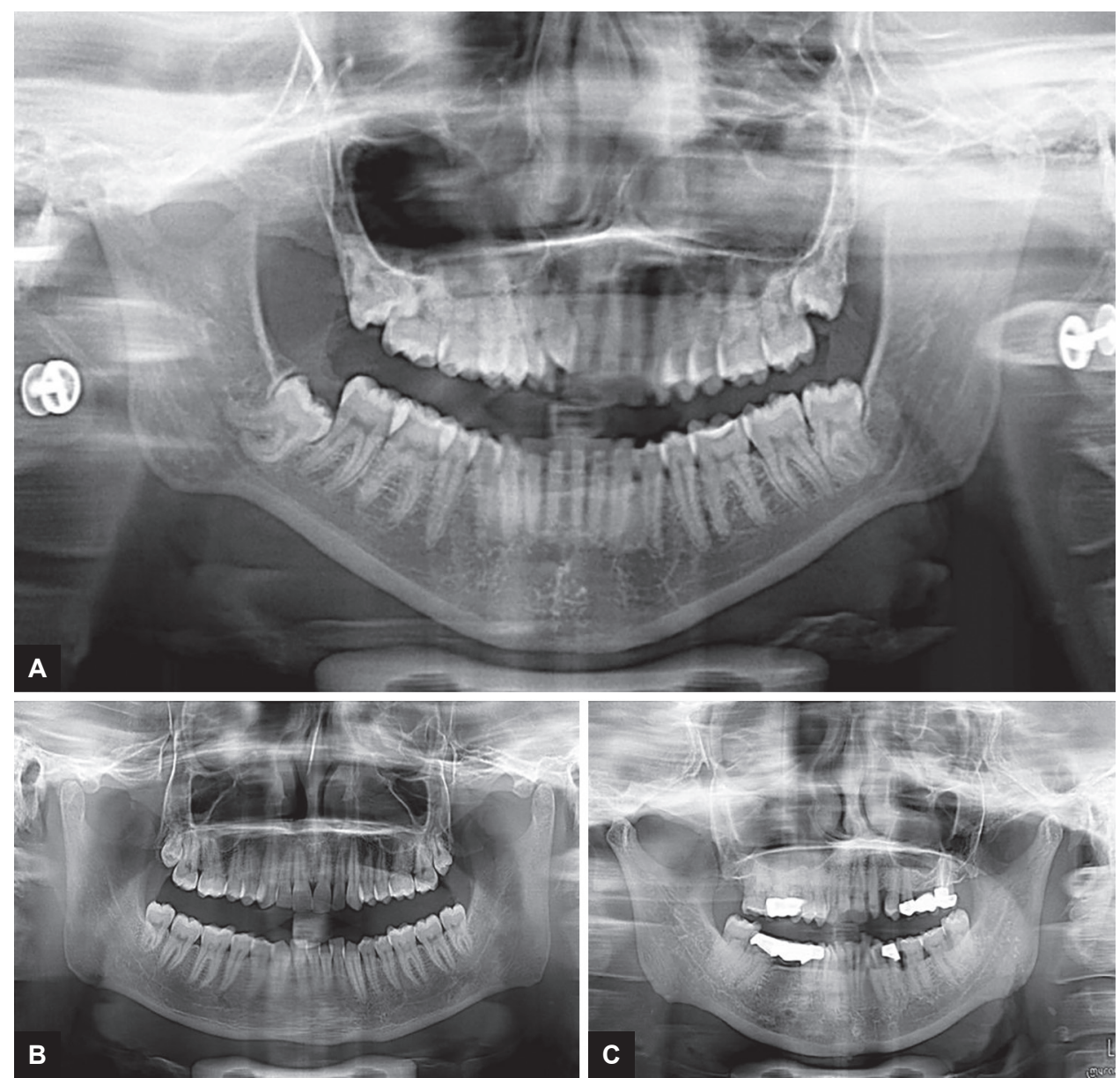

Figs 1A to C: Orthopantomogram showing: (A) Dilaceration of mesial and distal roots of 48; and (B) Microdontia involving maxillary molars; and (C) Concrescence of 47 and 48 


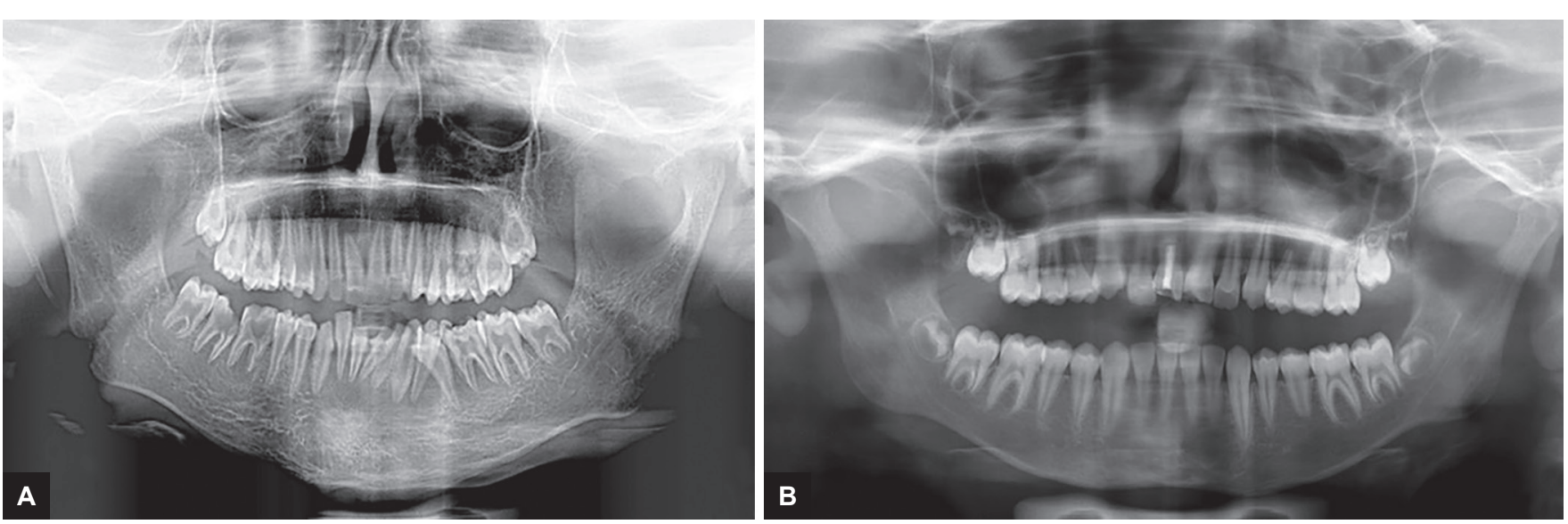

Figs 2A and B: Orthopantomogram showing: (A) Taurodontism involving all the maxillary and mandibular molars; and

(B) Talon's cusp in relation to maxillary right and left central incisor

Supernumerary roots refer to the development of increased number of roots compared to the normally described, which usually causes difficulty in endodontic procedures. ${ }^{3}$ Our study showed a prevalence of $0.83 \%$. Taurodontism is a variation that occurs in the tooth form where the tooth shows elongated crown or apically displaced furcation, which results in the pulp chamber that has increased length of the tooth (Figs 2A and B). This DA can be seen as an isolated incident, in families and associated with syndromes. ${ }^{20}$ Our study showed a prevalence of $0.28 \%$, which was very less when compared with other studies done by Goncalves-Filho et $\mathrm{al}^{9}$ and Darwazeh et $\mathrm{al}_{1}{ }^{21}$ who reported 27.19 and $8 \%$ respectively.

Talon's cusp resembles an Eagle's talon, which is an alteration of the tooth shape, i.e., characterized by the presence of an accessory cusp on the lingual or buccal face of an anterior tooth that projects from the cingulum (Figs 2A and B). ${ }^{16}$ Talon's cusp may fracture or be abraded as soon as the tooth comes into occlusion, exposing the pulp which cause endodontic complications. The prevalence ranges between 1 and $8 \%{ }^{2}$ Our results showed an occurrence of $0.37 \%$ which falls within this range. Concrescence is the cemental union of two adjacent teeth without confluence of the underlying dentin showing independent pulp chambers as well as root canals which usually affect the extraction of adjacent teeth (Figs 1A to C). ${ }^{2}$ In our study, the prevalence rate was $0.09 \%$, which was nearer to the findings of Goncalves-Filho et $\mathrm{al}^{9}$ where they observed the prevalence to be $0.63 \%$.

\section{CONCLUSION}

Our study showed that there was an overall prevalence of $35.27 \%$ DAs in the population studied where the anomaly related to shape was more when compared with those occurring in tooth size, position, and root number. These DAs are related to dental problems which should be known to dentists as they have greater clinical impact. Hence, their prevalence in different populations, early diagnosis, and treatment helps to avoid further complications.

\section{REFERENCES}

1. Thesleff I, Keränen S, Jernvall J. Enamel knots as signaling centers linking tooth morphogenesis and odontoblast differentiation. Adv Dent Res 2001 Aug;15:14-18.

2. Shrestha A, Marla V, Shrestha S, Maharjan IK. Developmental anomalies affecting the morphology of teeth - a review. RSBO 2015 Jan-Mar;12(1):68-78.

3. Neville, BW.; Damm, DD.; Allen, CM.; Bouquot, J. Oral and maxillofacial pathology. 3rd ed. Philadelphia: Elsevier; 2009. p. 77-99.

4. Hu JC, Simmer JP. Developmental biology and genetics of dental malformations. Orthod Craniofac Res 2007 May;10(2):45-52.

5. Bailleul-Forestier I, Molla M, Verloes A, Berdal A. The genetic basis of inherited anomalies of the teeth. Part 1: Clinical and molecular aspects of non-syndromic dental disorders. Eur J Med Genet 2008 Jul-Aug;51(4):273-291.

6. Guttal KS, Naikmasur VG, Bhargava P, Bathi RJ. Frequency of developmental dental anomalies in the Indian population. Eur J Dent 2010 Jul;4(3):263-269.

7. Seabra M, Macho V, Pinto A, Soares D, Andrade C. The importance of dental development anomalies. Acta Pediatr Port 2008;39:195-200.

8. Afify AR, Zawawi KH. The prevalence of dental anomalies in the Western region of Saudi Arabia. ISRN Dent 2012;2012:837270.

9. Goncalves-Filho AJ, Moda LB, Oliveira RP, Ribeiro AL, Pinheiro JJ, Alver-Junior SR. Prevalence of dental anomalies on panoramic radiographs in a population of the state of Pará, Brazil. Indian J Dent Res 2014 Sept-Oct;25(5):648-652.

10. Ezoddini AF, Sheikhha MH, Ahmadi H. Prevalence of dental developmental anomalies: a radiographic study. Community Dent Health 2007 Sep;24(3):140-144.

11. Uslu O, Akcam MO, Evirgen S, Cebeci I. Prevalence of dental anomalies in various malocclusions. Am J Orthod Dentofacial Orthop 2009 Mar;135(3):328-335.

12. Garn SM, Lewis AB, Kerewsky RS. X-linked inheritance of tooth size. J Dent Res 1965 Mar-Apr;44:439-441.

13. Baccetti T. A controlled study of associated dental anomalies. Angle Orthod 1998 Jun;68(3):267-274. 
14. Jafarzadeh H, Azarpazhooh A, Mayhall JT. Taurodontism: a review of the condition and endodontic treatment challenges. Int Endod J 2008 May;41(5):375-388.

15. Patil S, Doni B, Kaswan S, Rahman F. Prevalence of dental anomalies in Indian population. J Clin Exp Dent 2013 Oct;5(4):e183-e186.

16. Rajendran, R.; Sivapathasundaram, B. Shafer's textbook of oral pathology. 6th ed. Philadelphia: Elsevier; 2009. p. 38-44.

17. Chanchala HP, Nandlal B. Coexistent peg shaped mandibular central incisors along with maxillary lateral incisors: a rare case. Int J Oral Maxillofac Pathol 2012 Apr;3(1):65-68.
18. Dhanrajani PJ. Hypodontia: etiology, clinical features, and management. Quintessence Int 2002 Apr;33(4):294-302.

19. Papadopoulos MA, Chatzoudi M, Kaklamanos EG. Prevalence of tooth transposition. A meta-analysis. Angle Orthod 2010 Mar;80(2):275-285.

20. Regezi, JA.; Sciubba, JJ.; Jordan, RC. Oral pathology clinical pathologic correlations. 6th ed. St. Louis: Elsevier; 2012. p. 373-379.

21. Darwazeh AM, Hamasha AA, Pillai K. Prevalence of taurodontism in Jordanian dental patients. Dentomaxillofac Radiol 1998 May;27(3):163-165. 